\title{
Design and Implementation of a Single-Phase Energy Meter with SMS Controlled and Monitored Recharge Capability
}

\author{
Anthony Uwakhonye Adoghe, Victor Olugbenga Matthews, Peter Aigboviosa Amaize, Joseph Oluwole Oloweni, \\ Timilehin Fiyinfoluwa Sanni and Olayinka Ayo \\ Department of Electrical and Information Engineering, College of Engineering, Covenant University, PMB 1023, Ota, Ogun State, \\ Nigeria
}

Received: July 11, 2016 / Accepted: July 22, 2016 / Published: September 30, 2016.

\begin{abstract}
The Nigerian power sector is faced with poorly organized billing and consumer relations management. Tariff billing and collection has been a big problem in some community in Nigeria even with the introduction of prepaid meters. The process of payment is cumbersome and stressful as consumers have to go and pay in banks and then take tellers to power utility office to confirm their power bills payment before they can recharge their cards. The major purpose of this work is to design and implement a convenient, cashless, automated and transparent electricity metering, billing and payment system. This project combines the power electronic meter with a communications network which in this case is a GSM (global system for mobile) network. Remote electricity billing is a unique concept, in which the electricity board can collect the consumed units' data from consumer on mobile phone using GSM network. A unique property of this system is that, the electricity board can disconnect or reconnect consumers from remote location through the mobile phone. As this project works on GSM network, the system can be controlled from any part of the country.
\end{abstract}

Key words: Metering, billing, electricity board, prepaid meter.

\section{Introduction}

Energy is very important in all human activities in life [1]. The energy meter is an essential component of power supply. An energy meter is an instrument used to measure electrical energy consumption of electrical powered appliances in residential or business areas. Energy meter calibration is in billing units which are rated in kilowatt-hour ( $\mathrm{kWh}$ ). The kilowatt-hour is the amount of energy consumed by a load of one kilowatt over a period of one hour. Energy meter basically consists of voltage coils and current coils. The voltage coils measure the instantaneous voltage (volts) while the current coils measure the instantaneous current (amperes). The product of the instantaneous voltage,

Corresponding author: Anthony Uwakhonye Adoghe, M. Eng., Ph.D., associate professor, research fields: artificial intelligence in power system and energy management. current and power factor gives the instantaneous electrical power in wattage which is multiplied over a period of time. The increase in power consumption and the cost implication in per $\mathrm{kWh}$ have brought about the use of efficient energy appliances and monitoring [2]. Hence, metering is defined as a way of measuring and monitoring energy consumption [3].

The Nigerian power sector is faced with poorly organized billing and consumer relations management. Tariff billing and collection has been a big problem in Nigeria even with the introduction of prepaid meters. The process of payment is cumbersome and stressful as consumers have to go and pay in banks and then take tellers to power utility office to confirm their power bills payment before they can recharge their cards.

The major purpose of this work is to design and implement a convenient, cashless, automated and transparent electricity metering, billing and payment 
system. This system enables both electricity consumers and the utility company to remotely monitor the electricity consumption. It also allows the customer to remotely pay or "recharge" his/her meter. The system is effective and corruption free since the consumption can be measured remotely by the utility company and be cross-checked with revenue earned. This project combines the power electronic meter with a communications network which in this case is a GSM network.

Remote electricity billing is a unique concept, in which the electricity board can collect the consumed units' data from consumer on mobile phone using GSM network. Each consumer is provided with a unique energy meter, which is having a GSM modem, microcontroller unit and a display unit. An SIM (subscriber identity module) card is required for communication. Whenever this system receives an SMS (short message service) from electricity board, it calculates the number of units consumed and billing amount on the prevailing rate, displays on LCD (liquid crystal display) for user interface. This system also sends the same message to the electricity board for departmental information and database.

A unique feature of this system is that, the electricity board can disconnect or reconnect consumers from their remote locations through the mobile phone. As this project works on GSM network, the system can be controlled from any part of the country [4].

\section{Problem Statement}

Table 1 presents a set of data on energy received, energy billed and loss reduction indexes of a utility company in Nigeria for a period of six months.

Non-technical losses can be described as energy delivered to distribution system without being detected or accounted for within the limit of utility's capability. The unbundling of the utility industry in Nigeria has helped to create competitive edge and exposed the area of weakness and threats to the organization [5]. Figs. 1-4 revealed this weakness.

Table 1 Energy billed, delivered and customer's population.

\begin{tabular}{lllllllll}
\hline Month & $\begin{array}{l}\text { Energy } \\
\text { delivered } \\
(\mathrm{MWH})\end{array}$ & $\begin{array}{l}\text { Energy } \\
\text { billing } \\
(\mathrm{MWH})\end{array}$ & $\begin{array}{l}\text { Energy } \\
\text { losses } \\
(\mathrm{MWH})\end{array}$ & $\begin{array}{l}\text { Energy } \\
\text { billed } \\
(\%)\end{array}$ & $\begin{array}{l}\text { Customer } \\
\text { population } \\
\left(\times 10^{3}\right)\end{array}$ & $\begin{array}{l}\text { Customer } \\
\text { population } \\
\text { billed }\left(\times 10^{3}\right)\end{array}$ & $\begin{array}{l}\text { Response } \\
\text { to payment } \\
\left(\times 10^{3}\right)\end{array}$ & $\begin{array}{l}\text { Response } \\
(\%)\end{array}$ \\
\hline Sep' 2015 & 44,349 & 26,531 & 17,817 & 59.98 & 115.0 & 81.5 & 24.0 & 20.87 \\
Oct' 2015 & 44,089 & 28,982 & 15,179 & 65.55 & 116.5 & 8.0 & 22.0 & 18.88 \\
Nov' 2015 & 42,363 & 30,845 & 11,519 & 72.81 & 116.5 & 112.1 & 23.5 & 20.16 \\
Dec' 2015 & 42,916 & 30,549 & 12,367 & 71.18 & 115.6 & 83.0 & 24.0 & 20.58 \\
Jan' 2016 & 42,744 & 31,563 & 11,181 & 73.84 & 117.2 & 83.0 & 24.5 & 20.90 \\
Feb' 2016 & 45,605 & 32,219 & 13,386 & 70.65 & 116.9 & 82.5 & 21.0 & 17.96 \\
Total & 262,066 & 180,401 & 81,665 & 68.84 & 697.7 & 522.1 & 13.9 & 19.92 \\
\hline
\end{tabular}

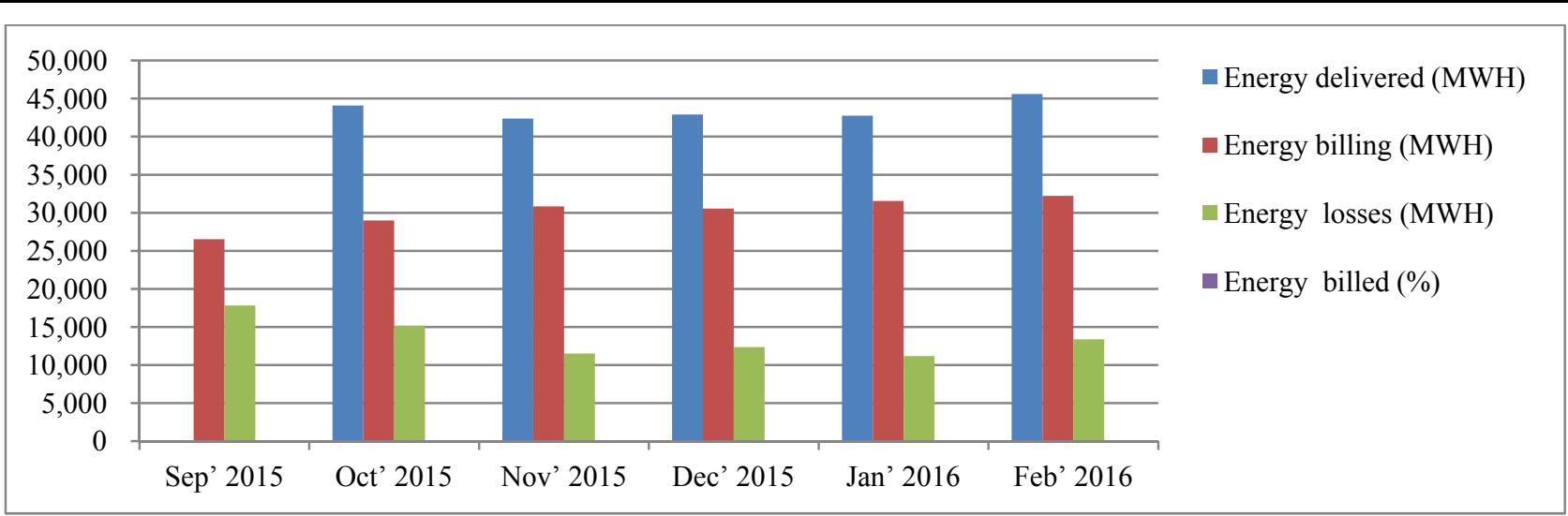

Fig. 1 Energy delivered lost and billed against month of the year. 


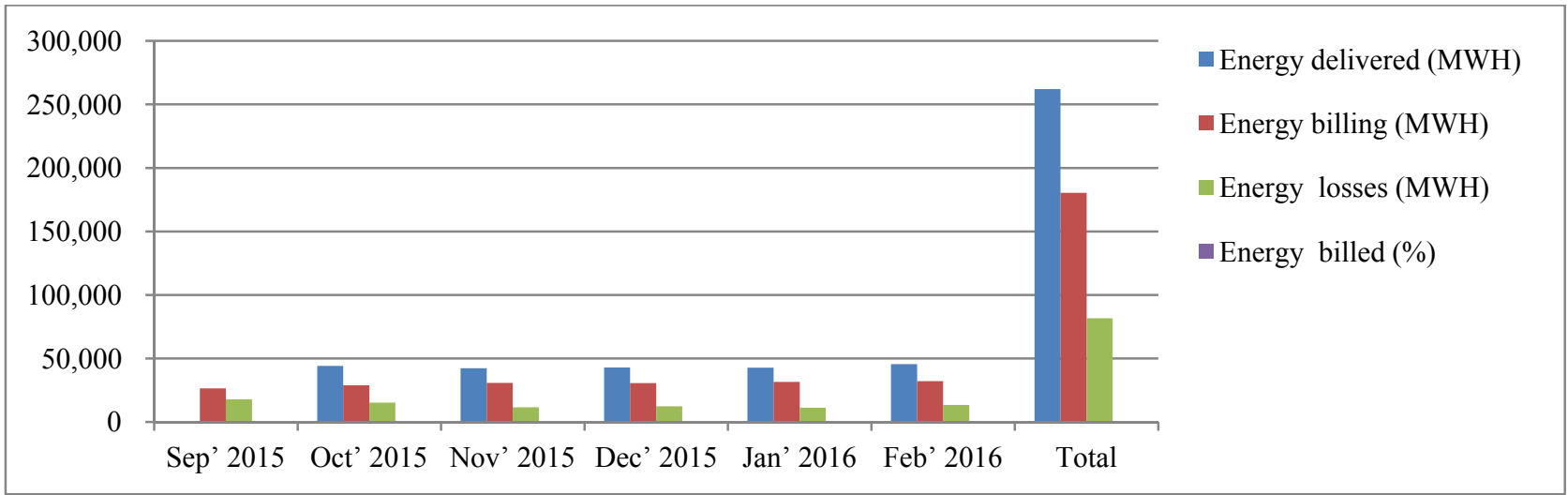

Fig. 2 Total energy delivered, the amount billed, lost and \% billed against month of the year.

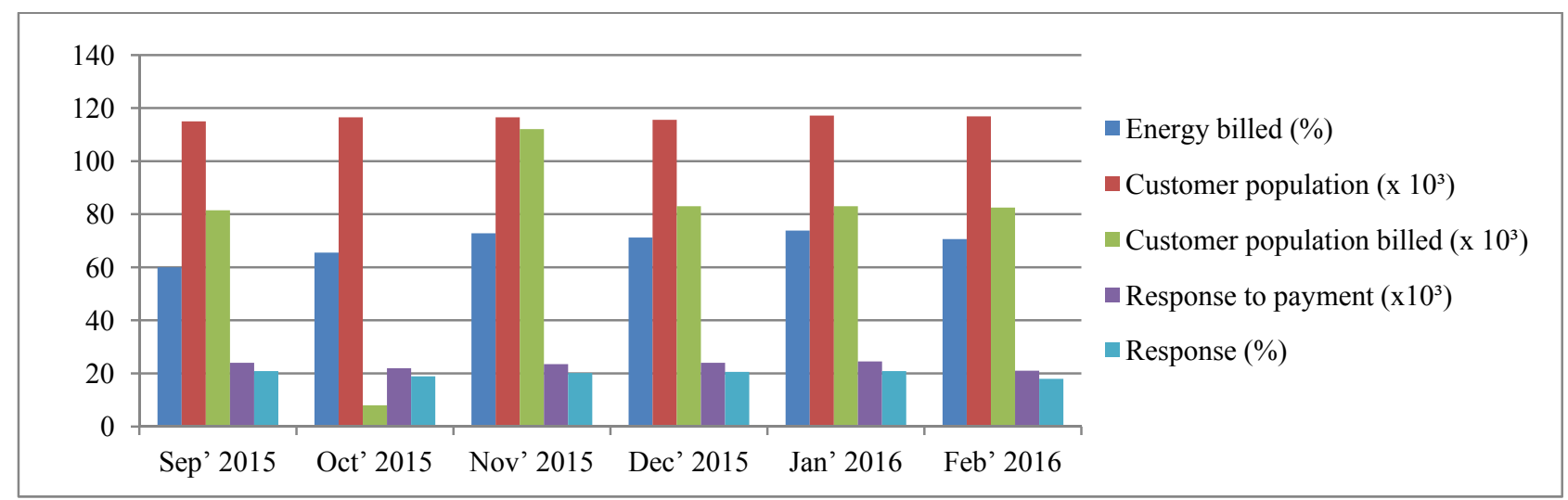

Fig. 3 Percentage of customers in the population that response to payment against month.

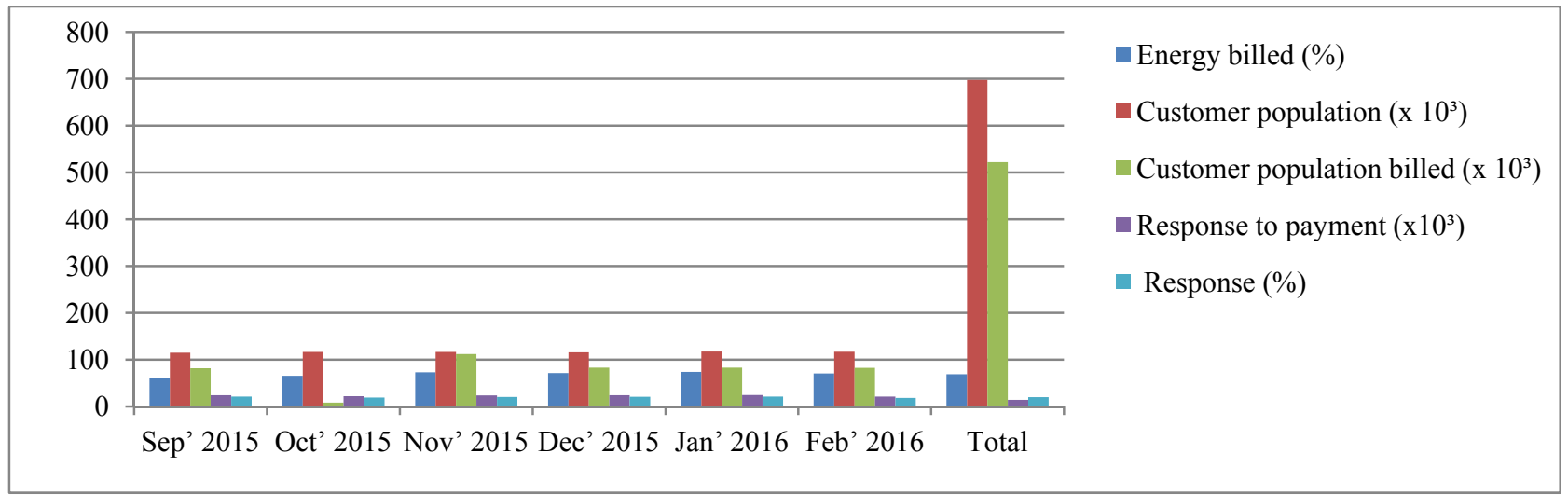

Fig. 4 Total customers in the population that response to payment against month.

The struggle for survival by the evolving companies has created the needed change in revenue collection process. According to World Bank recommendation, $87 \%$ of revenue billed must be collected to ensure the survival of the company [6]. There is need therefore, for the installation of a smart prepaid energy meter.

Low customers' responses to payment are often recorded on monthly basis as shown in Table 2 . When bills delivered do not correctly reflect the expectations of the customers, they decline payment as shown in the pie charts in Figs. 5 and 6, respectively.

\section{Implementation Objectives and Design Overview}

The aim of this design is to come up with a system that can measure energy consumption, recharge the 


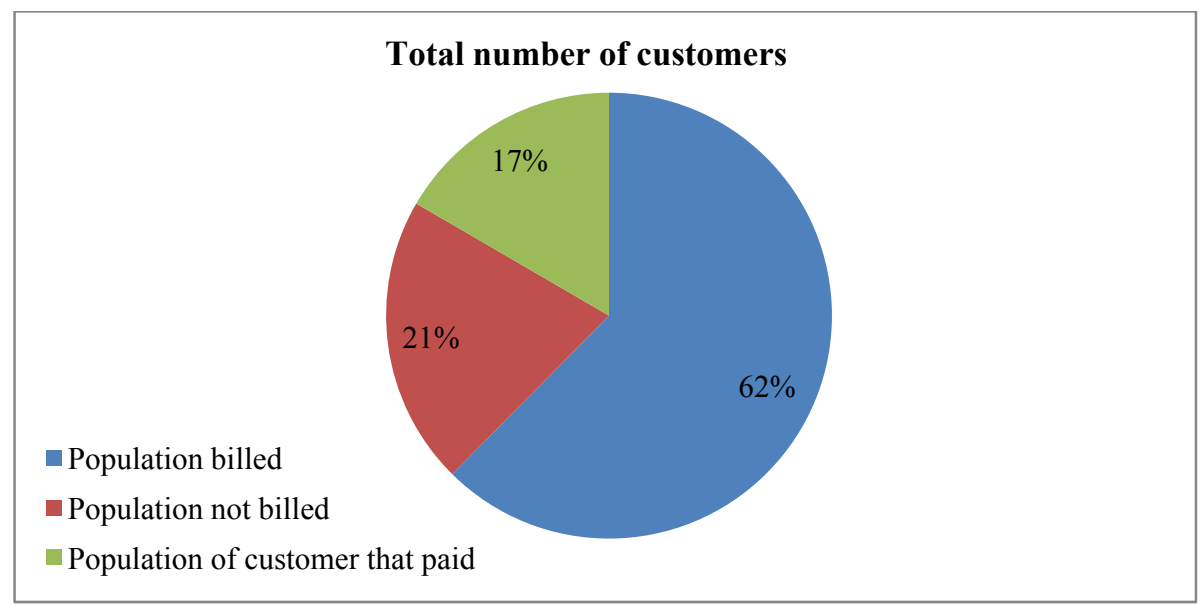

Fig. 5 Pie chart showing \% population of customers billed and not billed.

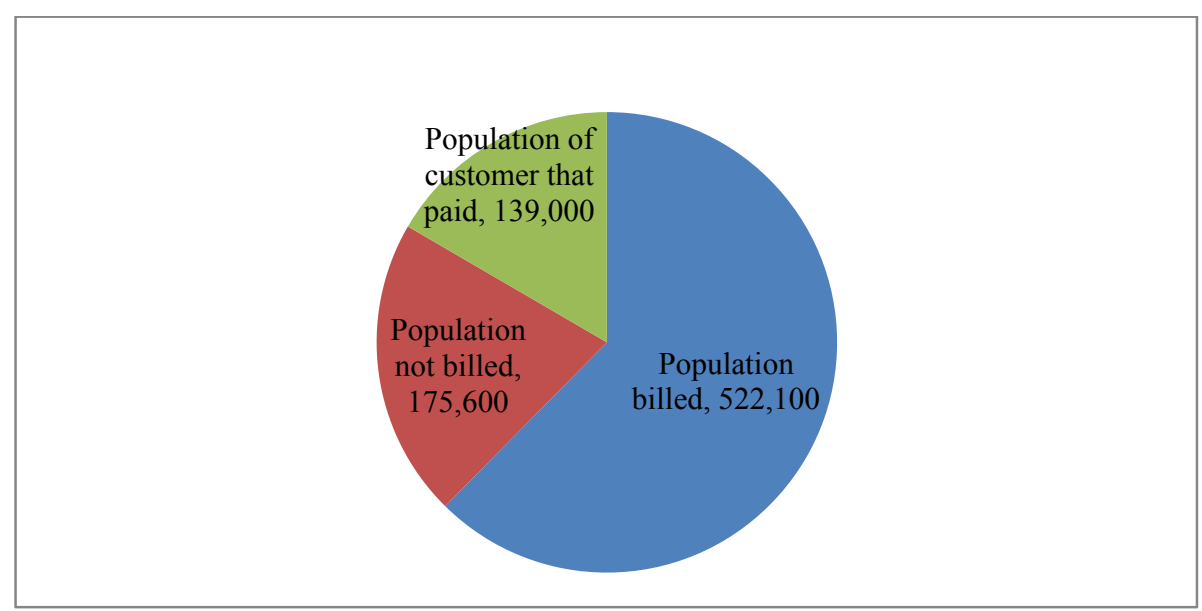

Fig. 6 Pie chart that outlines customer in the population that pays and does not pay bill.

Table 2 Customer population billed and those not billed, including those that paid.

\begin{tabular}{llll}
\hline Actions & No represented & Composition $(\%)$ & Degree $\left(^{\circ}\right)$ \\
\hline Population billed & 522,100 & 74.83 & 269.38 \\
Population not billed & 175,600 & 25.17 & 90.62 \\
Total & 697,700 & 100.00 & 360.00 \\
Population of customer that paid & 139,000 & 19.92 & 71.71 \\
\hline
\end{tabular}

meter via SMS and switch off the supply in case of zero credit balance. Some of the factors considered in the design are:

- Accuracy;

- Portability;

- Cost;

- Security.

The Meter Design is divided into the following modules:

- The voltage sensing module;
- The current sensing module;

- The metering chip;

- The main microcontroller;

- The display module;

- The communications module;

- The relay/switch off module;

- The power supply module;

- Meter design block diagram.

The entire process shown in block diagram in Fig. 7 can be described in the following steps: 
- Measurement of single-phase energy by the meter;

- Payment for prepaid energy credit through the GSM modem;

- Automatically crediting consumers and accounting for consumption as power is being used;

- Sending alerts when credit is running low;

- Disconnection of electrical power user on reaching zero credit balance;

- Sending energy consumption information to the power utility office;

- Remote disconnection via SMS;

- Protection of payment \& billing transactions.

The process in the development of the meter is broken down into the following steps:

- Creating a block arrangement of the system and how the separate units fit together;

- Determining appropriate components for individual system in Fig. 7;

- Designing a complete schematic diagram for the system based on the choice of components;

- Development of the appropriate circuit diagrams, components data sheets and command listings;

- Procurement of components;

- Assembly, testing, implementation and packaging;

- Providing appropriate conclusions and further recommendations.

The meter was implemented using ATMEGA32 IC to measure the voltage and current and integrating the product over time to give the energy usage $[7,8]$. The microcontroller is also the central system that interfaces with the meter, the LCD screen and the GSM modem as shown in Fig. 8. The microcontroller was programmed with the Keil $\mu$ vision compiler using C-language $[9,10]$.

\section{Testing and Construction}

The microcontroller calculates the energy value by integrating the value of Power over time by using the fundamental formula of Energy $=$ Power $\times$ Time.

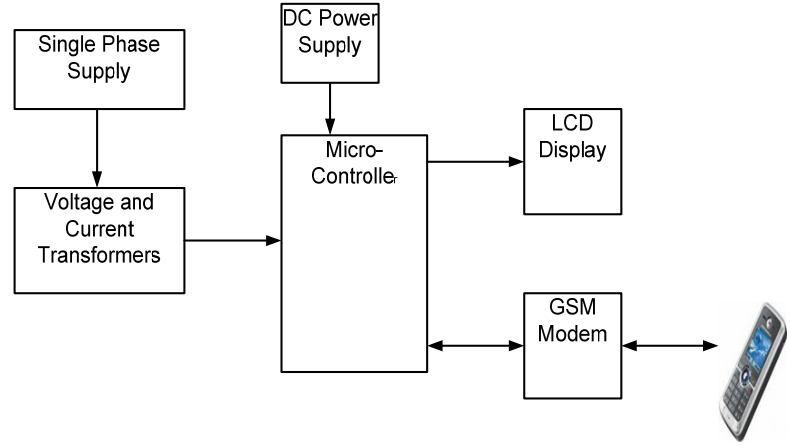

Fig. 7 Block diagram of the energy meter.

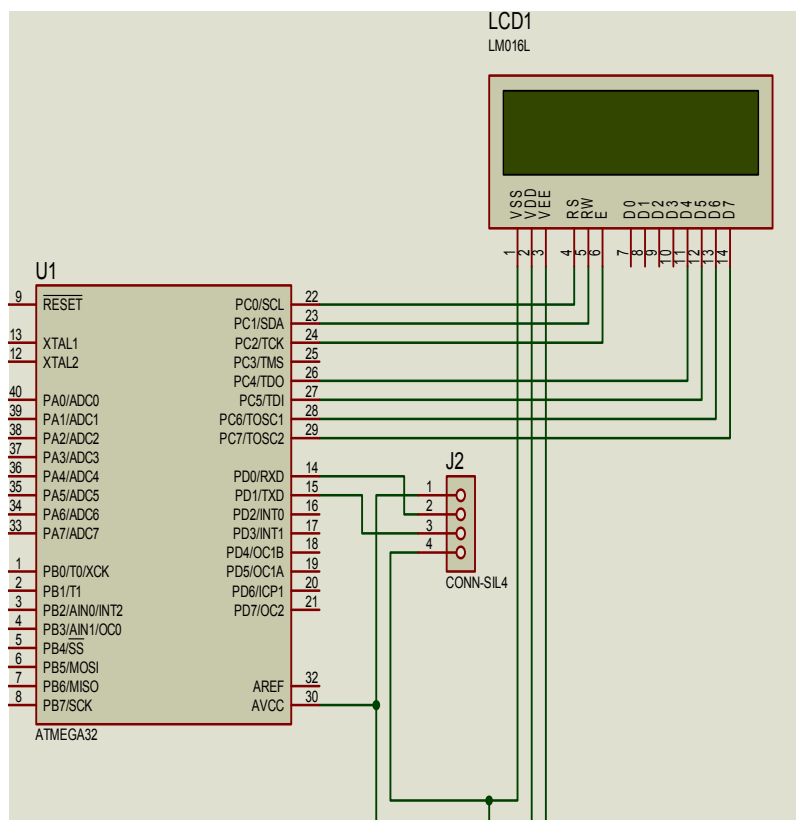

Fig. 8 The microcontroller interfaced with LCD screen.

The microcontroller also sends the output or energy consumed to the LCD screen via the output pins for display. The microcontroller receives the SMS messages from the GSM Modem and interprets it using the ATMEGA32 MCU command set. The microcontroller performs the following actions depending on the SMS message:

- Add credit units to the meter;

- Send out an SMS Message with the balance or send a signal to the relay to disconnect the meter;

- The microcontroller can both send and receive SMS messages via the GSM modem.

The display module is viewed through a $16 \times 2$ crystal display screen. The communication module uses mobile device communication system. The 
relay/switch off module controls the customer's connects and disconnect operation of the meter. Power supply unit energizes the microcontroller, relay and GSM module of the meter system.

\section{Key Benefits of the Developed Meter}

The developed prepaid meter meets the design objectives of being convenient, cashless, automated and transparent electricity metering, billing and payment system. The electricity board can disconnect or reconnect consumers from remote location through the mobile phone. The system is effective and corruption free, since the consumption can be measured remotely by the utility company and be cross-checked with revenue earned and finally the system enables electricity consumers to remotely recharge and monitor their electricity consumption.

\section{Conclusions}

In this work, a single-phase energy meter with SMS-controlled and remote recharge capability was designed and implemented with suitable and available materials so as to maximize utility of design. The field test result and analysis was found satisfactory. The developed energy meter is useful to power utilities since it enables them to generate timely bills. It enables utilities to understand energy demand patterns better, manage meter failures more effectively and check energy theft. It also helps consumers reduce the stress of going to utilities offices to pay and obtain recharge code for their meter and thereby manage their energy consumption more efficiently.

\section{References}

[1] Sambo, A. S. 2005. "Renewable Energy for Rural Development: The Nigerian Perspective." ISESCO Science and Technology 1 (May): 12-22.

[2] Bullbenkiene, V., Pecko, A., Zulkas, E., Kuprinavicius, A., Sokolov, A., and Mungaudis, G. 2011. "Energy Sub-Metering Data Acquisition System." Electronics and Electrical Engineering 5 (3): 99-102.

[3] Balakrishna. 2009. "Smart Grid and Metering Solutions: Overview." World Meter Design Corporating. Accessed July 20, 2011. http://freescale.com/smartenergy.

[4] Newbury, J., and Miller, W. 2001. "Multiprotocol Routing for Automatic Remote Electricity Meter Reading Using GSM Carrier Systems." IEEE Transactions on Power Delivery 16 (1): 1-5.

[5] Aswin, R. C., Aravind, E., Ramya, S. B., and Vasudevan, S. K. 2015. "Smart Meter Based on Real Time Pricing." Procedia Technology 21 (August): 120-4.

[6] Whyte, A. G. 1930. Forty Years of Electrical Progress. London: Ernest Benn Limited.

[7] Adoghe, A. U., Odigwe, I. A., and Igbinovia, S. O. 2009. "Power Sector Reforms-Effects on Electric Power Supply Reliability and Stability in Nigeria." International Journal of Electrical and Power Engineering 3 (1): 36-42.

[8] Sharma, S., and Shoes, S. 2011. "Design and Implementation of Wireless Automatic Meter Reading System." International Journal of Engineering Science and Technology 3 (3): 2329-34.

[9] Jain, A., and Bagree, M. 2011. "A Prepaid Meter Using Mobile Communication." International Journal of Engineering, Science and Technology 3 (3): 160-6.

[10] Omijeh, B. O., and Ighalo, G. I. 2013. "Design and Simulation of Single Phase Intelligent Prepaid Energy Meter." Journal of Innovative Systems Design and Engineering 4 (1): 17-29. 